\title{
ASYMPTOTIC BEHAVIOR OF SOLUTIONS OF IMPULSIVE NEUTRAL DIFFERENTIAL EQUATIONS WITH CONSTANT JUMPS
}

\author{
Cholticha Nuchpong, Sotiris K. Ntouyas, \\ PHOLLAKRIT THIRAMANUS AND JESSADA TARIBOON
}

\begin{abstract}
In this paper, we investigate the asymptotic behavior of solutions for a class of mixed type impulsive neutral delay differential equations with constant jumps. Sufficient conditions are given to guarantee that every non-oscillatory solution of the system tends to zero as $t \rightarrow \infty$. An example illustrating the result is also presented.
\end{abstract}

Mathematics subject classification (2010): 34K15, 34K20.

Keywords and phrases: Asymptotic behavior, neutral differential equation, impulsive differential equation.

\section{REFERENCES}

[1] K. Z. GuAn AND J. H. SHEN, Asymptotic behavior of solutions of a first-order impulsive neutral differential equation in Euler form, Appl. Math. Lett. 24 (2011) 1218-1224.

[2] J. H. SHEN AND Y. J. LiU, Asymptotic behavior of solutions of nonlinear neutral differential equations with impulses, J. Math. Anal. Appl. 322 (2007) 179-189.

[3] G. P. WeI And J. H. Shen, Asymptotic behavior for a class of nonlinear impulsive neutral delay differential equations, J. Math. Phys. 30 (2010) 753-763.

[4] A. ZHAO AND J. YAN, Asymptotic behavior of solutions of impulsive delay differential equations, J. Math. Anal. Appl. 201 (1996) 943-954.

[5] F. F. JIANG AND J. H. SHEN, Asymptotic behaviors of nonlinear neutral impulsive delay differential equations with forced term, Kodai Math. J. 35 (2012) 126-137.

[6] X. Z. LIU AND J. H. SHEN, Asymptotic behavior of solutions of impulsive neutral differential equations, Appl. Math. Lett. 12 (1999) 51-58.

[7] J. H. SHEN AND J. YU, Asymptotic behavior of solutions of neutral differential equations with positive and negative coefficients, J. Math. Anal. Appl. 195 (1995) 517-526.

[8] V. Lakshmikantham, D. D. Bainov and P. S. Simeonov, Theory of Impulsive Differential Equations, World Scientific, Singapore, 1989.

[9] A. M. Samoilenko And N. A. Perestyuk, Impulsive Differential Equations, World Scientific, Singapore, 1995.

[10] M. Benchohra, J. Henderson And S. K. Ntouyas, Impulsive Differential Equations and Inclusions, vol. 2. Hindawi Publishing Corporation, New York, 2006.

[11] F. JiAng AND J. SHEN, Asymptotic behavior of solutions for a nonlinear differential equation with constant impulsive jumps, Acta Math. Hungar. 138 (2013) 1-14.

[12] Y. Balachandran And G. Purushothaman, Asymptotic behavior of solutions for forced non linear delay impulsive differential equations, International Journal of Mathematical Trends and Technology (IJMTT) 9 (2014) 145-147.

[13] F. Jiang AND J. SUn, Asymptotic behavior of neutral delay differential equation of Euler form with constant impulsive jumps, Appl. Math. Comput. 219 (2013) 9906-9913. 